\title{
Corporate Socially Irresponsible Behavior and Its Spillover Effect: The Role of Upstream Versus Downstream Positions in the Supply Chain: An Abstract
}

\author{
Zhuofan Zhang
}

\begin{abstract}
Does a scandal lead to a decline in firm financial performance? Previous studies have shown inconclusive results for the relationship between a firm's corporate social performance (CSP) and financial performance. Based on signaling theory, I hypothesize that the strength of this relationship depends on the position of the firm in the supply chain. Specifically, I propose that the actions of firms positioned in the downstream end of the supply chain are more visible to consumers than those from firms upstream the supply chain. Consequently, the link between CSP and financial performance will be stronger for firms in the downstream, rather than upstream, the supply chain. In addition, I contend that the spillover effect from irresponsible social behaviors will also be stronger for firms downstream rather upstream the supply chain.
\end{abstract}

References Available Upon Request

Z. Zhang $(\bowtie)$

The University of Texas at El Paso, El Paso, TX, USA

e-mail: zzhang2@miners.utep.edu 